\title{
CALIDAD ECOLÓGICA DEL RÍO VILLETA \\ (Villeta - Cundinamarca)
}

\section{María Victoria Ruiz Chavarro* María Eugenia Rincón Hernández}

\begin{abstract}
In this work the composition and the spatial distribution of a community of aquatic insects were studied in order to asses the ecological quailty of Villeta River located in the Deparment of Cundinamarca. The hidrologic characteristics of this lotic systerm were also investigated in order search for biotic and abiotic interactions. From February: 1999 to January 2000, samples from two localities were taken monthly and subjected to physicochemical and biological analysis. The most important famlies were Chironomidae (Diptera), Baetidae (Ephemeroptera) and Hydropsychidae (Trichoptera) Both the physicochemical and biological characteristics of this ecosystem are rainfall pattern dependent.
\end{abstract}

\section{RESUMEN}

En esta investigación se estudió la composición y distribución de la comunidad de insectos acuáticos del río Villeta localizado en el departamento de Cundinamarca, con el fin de establecer la calidad ecológica del agua; así como también su relación con las variaciones de los parámetros hidrológicos, físico-químicos y biológicos en periodos de alta y baja precipitación. Las muestras se tomaron mensualmente en dos estaciones a partir de Febrero de 1999 hasta Enero de 2000. Las familias más importantes fueron: Chironomidae (Diptera), Baetidae (Ephemeroptera) e Hydropsychidae (Trichoptera). Tanto las características fisicoquímicas como las biológicas están reguladas por los periodos de alta y baja precipitación.

Palabras claves: Comunidad, coriotopos, insectos acuáticos, calidad ecológica del agua.

\section{INTRODUCCIÓN}

A pesar de que en nuestro país los macroinvertebrados acuáticos y especialmente los estados inmaduros de los insectos acuáticos se han venido utilizando como indicadores de la calidad ecológica del agua; sin embargo, el uso de éstos organismos como bioindicadores no siempre se ha hecho de manera correcta, puesto que el grado de resolución taxonómica ha sido demasiado general y las técnicas de colección empleadas no han permitido conocer de manera más precisa su composición y distribución espacial.

Los organismos tienen cierta tolerancia a las diferentes condiciones del medio acuático y a través de ellos se puede calificar los cuerpos de agua por grados de calidad. El

\footnotetext{
* Licenciada en Biología, Universidad Pedagógica Nacional.

${ }^{* *}$ Profesora Departamento de Biología, Universidad Pedagógica Nacional. Merincon01@starmedia.com
} 
estudio de todo el sistema es complejo y por ello en los diferentes estudios hay que limitarse a algún tipo de organismo (Prat, 1997).

El uso de los insectos acuáticos como indicadores de la calidad de agua, tiene gran aceptación entre los ecólogos y es uno de los métodos más utilizados en la evaluación de los impactos ambientales causados por el desarrollo de proyectos de ingeniería (represas, minas, carreteras y otros) que en alguna forma van a afectar los ecosistemas acuáticos.

Según Roldán (1992), los macroinvertebrados son organismos que se adaptan o perecen en condiciones adversas por lo tanto el tipo de comunidad que se encuentre en el ecosistema debe reflejar las condiciones ambientales que allí están prevaleciendo.

Las especies denominadas euritípicas se caracterizan por tolerar amplios rangos ambientales y, por tanto, presentan gran diseminación en la dimensión espacio- temporal de los ecosistemas. Las especies estenotípicas, son aquellas que por el contrario se desarrollan bajo condiciones ambientales muy precisas dado los estrechos rangos de tolerancia ambiental, por lo que su presencia esta restringida en tiempo y espacio a condiciones particulares de los ecosistemas (Ramírez 1998).

Las ventajas de usar macroinvertebrados como indicadores biológicos son en primera instancia indicadores sencillos y tienen ciclos de vida largos, facilidad en su recolección y son los más utilizados, tiene poca variabilidad genética, son sedentarios de fácil identificación taxonómica y son sensibles a los cambios bruscos en el ecosistema. Entre las desventajas, está la de hacer un muestreo cuantitativo y la presencia de grupos heterogéneos.

La calidad ecológica del río Villeta, se ve afectado principalmente por el vertimiento de aguas servidas domésticas y escorrentía superficial de terrenos agrícolas de las zonas aledañas, debido a que no hay plantas de tratamiento en éste Municipio. Este manejo inadecuado afecta directamente a las comunidades acuáticas y especialmente a la distribución de los insectos acuáticos en este sistema.

Debido a que el Río Villeta ha sido poco estudiado en cuanto a sus características fisicoquímicas y biológicas, el presente trabajo pretende determinar la composición y distribución espacial de los principales grupos de insectos acuáticos en el río Villeta y analizar su relación con la calidad del agua. Esta investigación, hace parte del proyecto de Investigación. 'Trichoptera del Departamento de Cundinamarca y su relación con la Calidad de Agua'. Financiado por COL-CIENCIAS. Y La Universidad Pedagógica Nacional.

\section{METODOLOGIA}

Los muestreos se realizaron mensualmente, entre febrero de 1999 y enero de 2000 cubriendo periodos de alta y baja precipitación. Se ubicaron dos (2) estaciones de muestreo; la primera se localizó antes del pueblo de Villeta a 1000 m.s.n.m y la segunda después a 800 m.s.n.m. El lecho del río esta constituido especialmente por rocas de gran tamaño y piedras, la ribera en ambos lados del cauce y en ambas estaciones presenta escasa vegetación lo cual incide en la ocurrencia de frecuentes deslizamientos.

En cada sitio se tomaron muestras de las formas inmaduras y de los adultos. Los estados inmaduros de los macroinvertebrados se muestrearon en un área de $10 m$ cuadrados mediante la técnica de los coriotopos Rincón(1996). Teniendo en cuenta la 
heterogeneidad espacial del río, en cada estación se establecieron seis (6) coriotopos: Hojarasca $(\mathrm{H})$, gravilla (Grav), piedra corriente rápida y lenta (PCR y $\mathrm{PCL}$ ), zona de salpicadura (Salp) y roca en cascada (R); además, se utilizaron algunas técnicas tradicionales propuestas por Roldán(1988) como la red de surber.

Para la captura de adultos de algunos órdenes se emplearon trampas de luz blanca y negra; igualmente se utilizaron trampas de alcohol al $90 \%$ y agua; las cuales se ubicaron en el centro del sistema lótico entre las 6:00 PM y las 9:00 PM.

Se analizaron variables fisicoquímicas como: temperatura del agua y del ambiente, oxígeno disuelto, porcentaje de saturación de oxígeno, velocidad de la corriente, conductividad, amplitud del cauce, profundidad, turbiedad, color, $\mathrm{pH}$, alcalinidad total, acidez total, C02 libre, dureza total, calcio, amonio, cloruros, fosfatos, sólidos disueltos totales y porcentaje de materia orgánica. Para evaluar las variaciones del caudal se analizaron los datos tomados en la estación hidrométrica de Villeta, localizada cerca al segundo punto de muestreo a $790 \mathrm{msnm}$.

Para la determinación de los diferentes grupos de insectos acuáticos se utilizaron las claves de Lopretto (1995), Merrit \& Cummins (1996), Muñoz \& Ospina (1999), Ruíz et al (2000) y Domínguez et al (2001). Para la identificación de los Trichoptera adultos se utilizaron las claves de Flint (1983 y 1991), Angrisano (1995) y para los inmaduros Roldán (1988>, Wiggins (1996). Igualmente se contó con la colaboración del doctor Oliver Flint del Smithsonian institution (Washington- USA) para corroborar las determinaciones de los adultos de este grupo.

Para el análisis e interpretación de los resultados fisicoquímicos y biológicos de los diferentes grupos de insectos acuáticos, se utilizaron técnicas de clasificación y ordenación, previa normalización logarítmica de los datos $(\log X+1)$.

Para evaluar la calidad biológica del agua se utilizo el BMWP (Biological Monitoring Working Party>, que constituye un método simple y rápido para evaluar la calidad del agua usando los macroinvertebrados acuáticos como bioindicadores. El método solo requiere llegar hasta el nivel de familia y los datos son cualitativos (presencia/ ausencia>. El puntaje va de 1 a 10 de acuerdo con la tolerancia de los grupos a la contaminación orgánica. Las familias más sensibles reciben un puntaje de 10; en cambio las más tolerantes a la contaminación reciben una puntuación de 1. Se utilizaron los puntajes dados por Roldán (2000) quien realizo una adaptación preliminar de este método para Colombia. 


\section{RESULTADOS Y DISCUSIÓN}

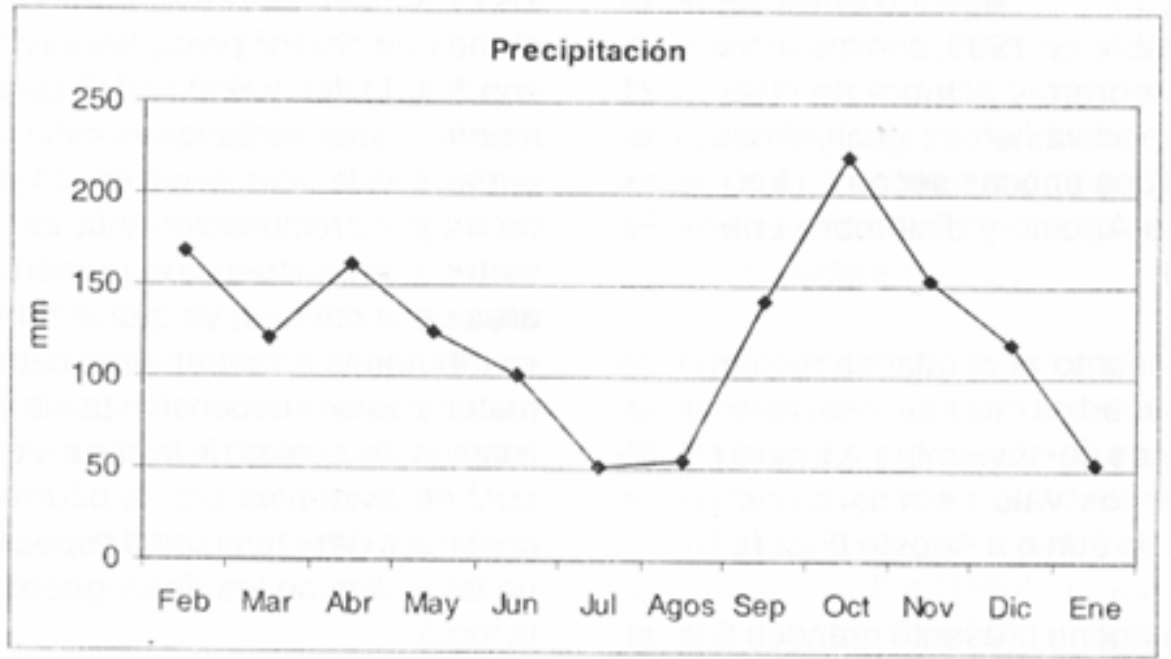

Fig. 1. Variación de la precipitación para el año de muestreo, en la estación La Esperanza. Villeta 1350 msnm Villeta - Cundinamarca (1350 msnm).

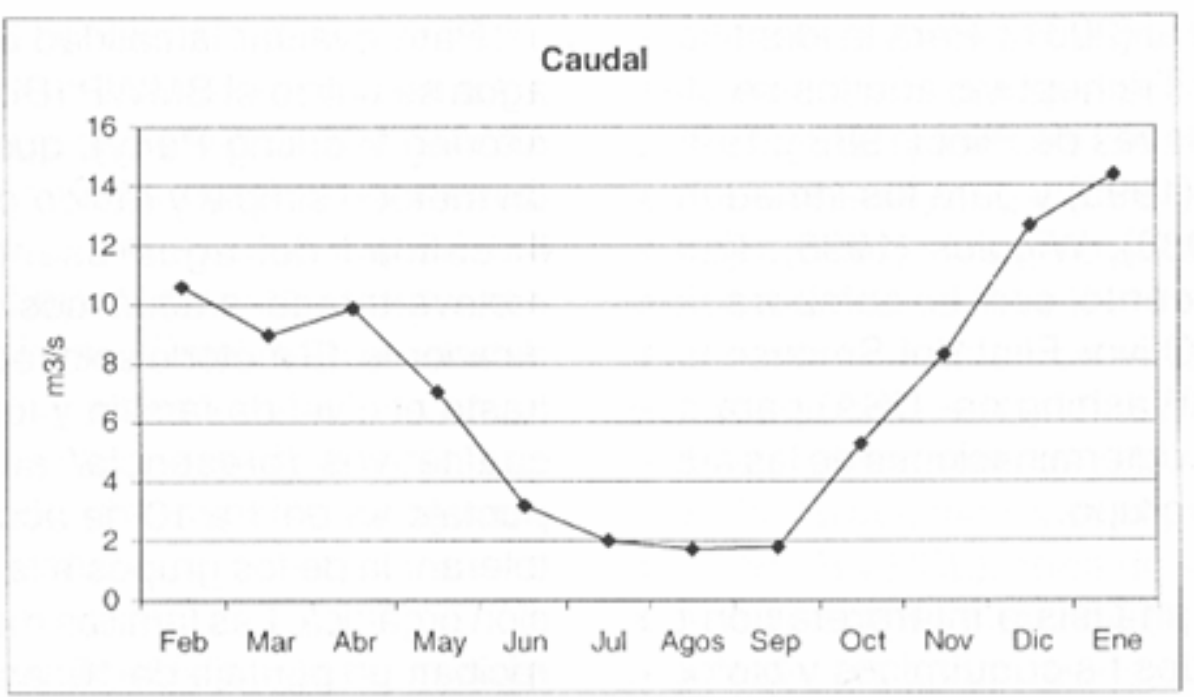

Fig. 2. Valores mensuales multianuales del caudal (1989- 1999), en la estación hidrometrica de Villeta Villeta-Cundinamarca (700 msnm).

Desde el punto de vista climático, la zona presenta un régimen de precipitación bimodal, teniendo en cuenta los promedios mensuales registrados para el año 1999 en la estación La Esperanza (1350 msnm), se observan dos periodos de lluvia, el primero en los meses de febrero-abril y el segundo entre septiembre-octubre de 1999, con máximos valores en febrero y octubre de (169 y $221 \mathrm{~mm}$ respectivamente); igualmente se presentan dos épocas secas en los meses de junio-Agosto y diciembre-enero (Figura 1).

En cuanto al caudal se registran los valores medios multianuales máximos en los meses de noviembre a Enero $(12.65 \mathrm{~m} 3 / \mathrm{s})$ y los valores más bajos en los meses de Junio a Agosto (Figura 2).

El oxígeno-presentó grandes fluctuaciones a lo largo del periodo de estudio especialmente en la estación 2, registrando en el mes de marzo el valor más bajo 
(2.9mg/l> y en los meses de septiembre y octubre los valores más altos $(7,6 \mathrm{mg} / \mathrm{l})$; en la estación 1 oscilo entre 5,6 mg/l y $8.2 \mathrm{mg} / \mathrm{l}$; los mayores valores en este parámetro coinciden con los niveles altos de caudal (Matthias \& Moreno 1983).

La turbiedad fluctuo ampliamente en las dos estaciones; el mínimo valor se observó en el mes de julio con 1.5 UNT y los máximos valores se presentaron en el mes de mayor precipitación octubre, con 8200 UNT y 6000 UNT respectivamente. Estas variaciones están relacionadas con la ocurrencia de los periodos de mayor precipitación y la entrada de material en suspensión procedente del área de la cuenca, ya que el río Villeta y su tributarios arrastran gran cantidad de materiales en suspensión por la inestabilidad de los suelos de la zona aledaña, lo cual se evidencia por la ocurrencia de continuos deslizamientos especialmente en las orillas de los ríos y quebradas de la región.

Según Roldán (1992) los ríos y embalses ubicados en zonas bajas, son muy turbios debido al arrastre de materiales, ya que en éstas zonas algunos de éstos son solubles por el agua cargada de ácido carbónico que se filtra entre las rocas. Parámetros como el porcentaje de materia orgánica, hierro y magnesio también están relacionados con las épocas de alta precipitación de la región.

Con respecto a la acidez, en las dos estaciones se presentan variaciones a lo largo del año, se presentan dos picos en los meses de mayo y julio (14 y 12 mg/CaCO3 respectivamente), coincidiendo con los valores máximos de $\mathrm{C} 02$ en estos mismos meses (6,2 y 5,2 mg/l CO2 respectivamente). La acidez proviene del C02 producto de la respiración de los organismos por descomposición de la materia orgánica, ya sea por un sistema aeróbico o anaerobio (Benavides et al 1993).

El río Villeta presenta aguas duras en las dos estaciones y su dureza está representada principalmente por el ion calcio. En la estación 1 la dureza total presenta poca variación, el valor mínimo se encontró en octubre (250mg!l CaCO3) y el máximo en marzo (390mg!l CaCO3); mientras que en la estación 2 se registraron valores muy altos en noviembre $(1500 \mathrm{mg} / \mathrm{l})$ y el mínimo se registró en el mes de octubre (300mg!l); coincidiendo estos bajos valores con la época de mayor precipitación, esto es explicable por el efecto de una mayor dilución en zonas tropicales con abundantes precipitaciones y oxidación de residuos orgánicos, condiciones que favorecen la disolución y por lo tanto la disminución de la dureza del agua. (Benavides et al 1993).

En general los valores registrados para la mayoría de los parámetros fisicoquímicos son altos en relación con los reportados para otros sistemas acuáticos de la región andina de Cundinamarca (González et al 2001) y de otras regiones, (Roldán 1992), especialmente variables como la conductancia (860 microhoms!cml), sólidos disueltos totales (7200mg!l), cloruros (24 mg/l Cl-), sulfatos (1380 mg/l SO4), hierro (9.2 mg/l Fe +3) que alcanzaron valores máximos en la estación 2, principalmente en el mes de noviembre.

El río Villeta presenta valores muy altos de cloruros en la estación 2, debido posiblemente a la contaminación por aportes de aguas residuales, aumentando la concentración de cloruros por excretas humanas, especialmente en la orina; mientras que las aguas de ríos de la parte alta presentan contenidos muy bajos de cloruros(menor de 5 mg/l). (Roldán 1992).

Igualmente a lo largo del año se obtuvieron valores muy altos en las concentraciones de sulfatos. En la estación 2 se registran valores máximos (1380 mg/l S04) en el mes de 
noviembre; correspondiendo a las épocas de mayor caudal, por consiguiente incrementando la disolución del sustrato (Esteves 1988). Los valores mínimos en las dos estaciones se registraron en el mes de febrero (200 y 210 mg/l SO4 respectivamente),

Según Machado \& Roldán (1 981) la concentración normal de éste lon en aguas naturales se encuentra entre 6.0 y $10.0 \mathrm{mg} / \mathrm{l}$ S04 por lo tanto el río sobre-pasa éstos valores de manera significativa, según Roldán (1992) a causa de la contaminación doméstica, que para el caso del Río Villeta proviene del Municipio de Villeta y de los tributarios especialmente de la quebrada Cune.

El régimen pluviométrico parece ser el factor más importante para determinar el comportamiento de las variables fisicoquímicas del río Villeta, ya que su comportamiento depende de las épocas de alta y baja precipitación así como de las variaciones de caudal, esto se corrobora con el Biplot de componentes principales (Figura 3), donde se observa que los meses de Enero y Noviembre presentan características disímiles, Enero (época de baja precipitación) se caracteriza por tener en las dos estaciones los valores más bajos en cuanto a la dureza total, calcio, conductividad y cloruros, mientras que el mes de Noviembre presento los valores más altos de alcalinidad total, magnesio, conductividad, sólidos disueltos totales, cloruros, sulfatos especialmente en la estación 2. Julio y Agosto se caracterizaron por los valores más altos en las concentraciones de ortofosfatos y amonio y los valores más bajos en la concentración de hierro en las dos estaciones.

\section{Aspectos biológicos}

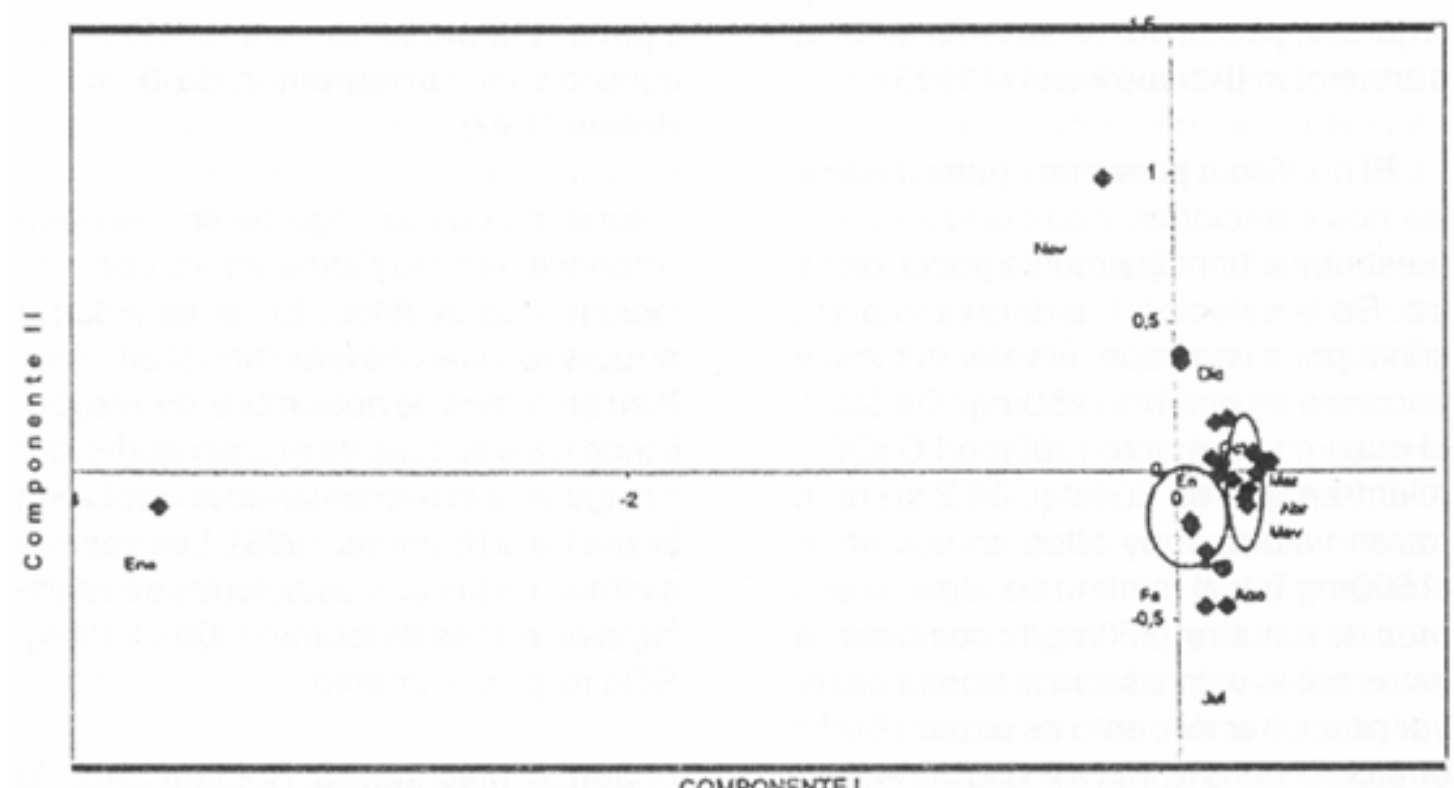

COMPONENTEI

Fig. 3. Biblop de componentes principales (PCA) entre meses de muestreo para las variables fisicoquimicas. Rio Villeta (Cundinamarca)

Durante el periodo de estudio se colectaron 8134 individuos por el método de coriotopos y por métodos tradicionales Surber 830 organismos, distribuidos en 4 ordenes y 22 familias. El orden que registró mayor número de familias fue Díptera (14 familias), seguido de Ephemeroptera (3 familias), Trichoptera (3 familias) y Coleóptera (1 familia), con abundancias relativas de $61.18 \%, 27.31 \%, 10.48 \%$ y $1.09 \%$ res pectivamente. 
Para el orden Trichoptera se registraron 5 géneros: Smicridea, Leptonema,Alisotrichia, Hydroptila y Helicopsyche. El género más constante fue Smicridea (morfotipo spl) pues se encontró en la mayoría de los muestreos; igualmente presento los mayores valores de abundancia $(7.82 \%)$ en épocas de baja precipitación y caudal bajo (julio y agosto) (Figura 4). Con respecto a los adultos en el mes de Julio se determinaron 24 machos y 30 hembras de Smicridea probolophora.
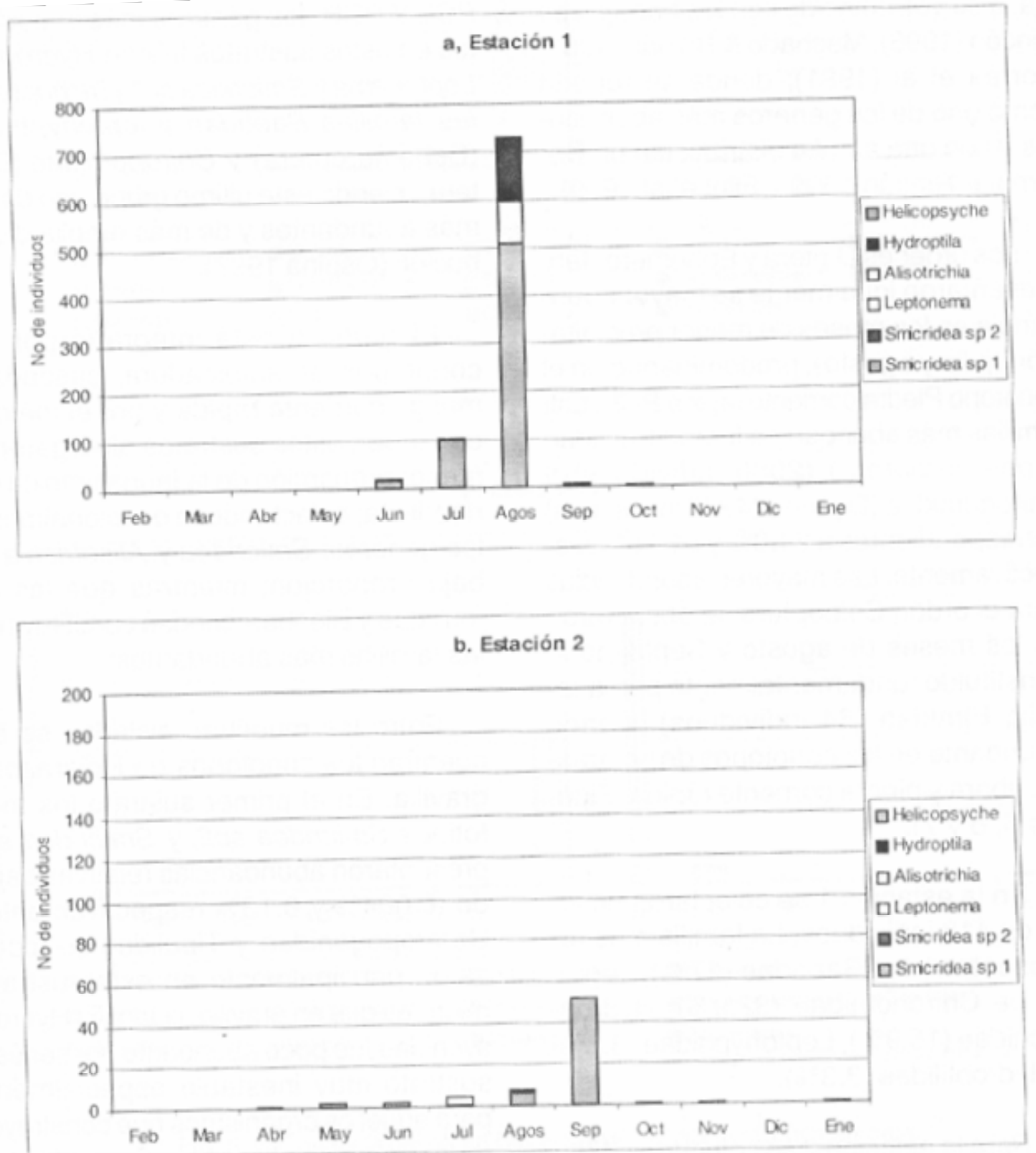

Fig. 4. Abundancia de los Trichoptera en el Río Villeta - Cundinamarca 
Este género presenta adaptaciones tanto morfológicas como fisiológicas que le permiten construir refugios y fijarlos a un sustrato estable y de esta forma soportar las variaciones de la corriente en épocas de altas precipitaciones Uribe et al (1996). Según Mangeaud (1999) éste género es muy tolerante a contaminantes, en muchos casos es dominante cuando la contaminación es leve o intermedia, a su vez coincide con los trabajos de Rincón (1996), Machado \& Roldán (1981) Correa et al (1981); donde se reporta como uno de los géneros más abundantes y con una amplia distribución en Colombia (Rincón 1999 y Flint et al 1999).

Los ordenes Díptera y Ephemeroptera presentaron igualmente su mayor abundancia en los meses de menor precip itación (julio y agosto), predominando en el coriotopo Piedra corriente rápida PCR. Las familias más abundantes fueron Baetidae (Ephemeroptera) (2080 individuos) y Chironomidae (Diptera) (4278 individuos) correspondientes a $24.8 \%$ y $51.15 \%$ respectivamente. Las mayores abundancias para el orden Coleoptera se observaron en los meses de agosto y Septiembre; constituido fundamentalmente por la familia Elmidae (64 individuos), siendo abundante en los coriotopos de hojarasca, ribera y piedra corriente rápida (Figuras 5, 6 y 7).

En la estación 1 se colectaron un total de 418 individuos. La familia más representaiva fue Baetidae (37\%); seguida de Chironomidae (32.9\%), Hydropsychidae (15.9\%), Leptohyphidae (3.8\%) e Hydroptilidae (3.3\%).

Para la estación 2 se colectaron 4783 organismos destacándose las familias Chironomidae (73.38\%), Baetidae (13.11\%) y simuliidae (7.59\%). Las demás presentaron abundancias relativas inferiores a $1.55 \%$.

En el análisis de componentes principales entre coriotopos se reafirme la relación entre los coriotopos y los grupos de insectos presentes en este sistema lótico (Figura 8). Se observan 2 grupos, el grupo 1 representado por los coriotopos PCL Y PCR, los géneros más importantes en estos sustratos fueron Hydroptila, Leptonema y Smicridea spl (Trichoptera); las familias Baetidae y leptohyphidae (Ephemeroptera) y Chironomidae (Dipte re), siendo éste último grupo uno de los más abundantes y de más amplia distribución (Ospina 1997).

El grupo II está integrado por los coriotopos de salpicadura, cascada y musgo corriente rápida y por el método de surber, estos sustratos albergaron la menor proporción de la fauna límnica del río Villeta; colectandose ocasionalmente los géneros: Smicridea y Alisotrichia en baja proporción; mientras que las Simuliidae y Blepharoceridae constituyeron las familias más abundantes

Entre las muestras aisladas se encuentran los coriotopos de Hojarasca y gravilla. En el primer sustrato los morfotipos Smicrídea sp2, y Smicridea $s p$ presentaron abundancias relativas bajas de $(0.004 \%$ y $0.13 \%$ respectivamente); Ceratopogonidae y Tipulidae se localizaron principalmente en este sustrato, mientras que en gravilla, la familia Hydropsychidae fue poco abundante por ser éste sustrato muy inestable especialmente para aquellos organismos que construyen redes como es el caso de Smicridea sp1 y sp2 y Leptonema (Hydropsychidae) (Rincón 1999). 

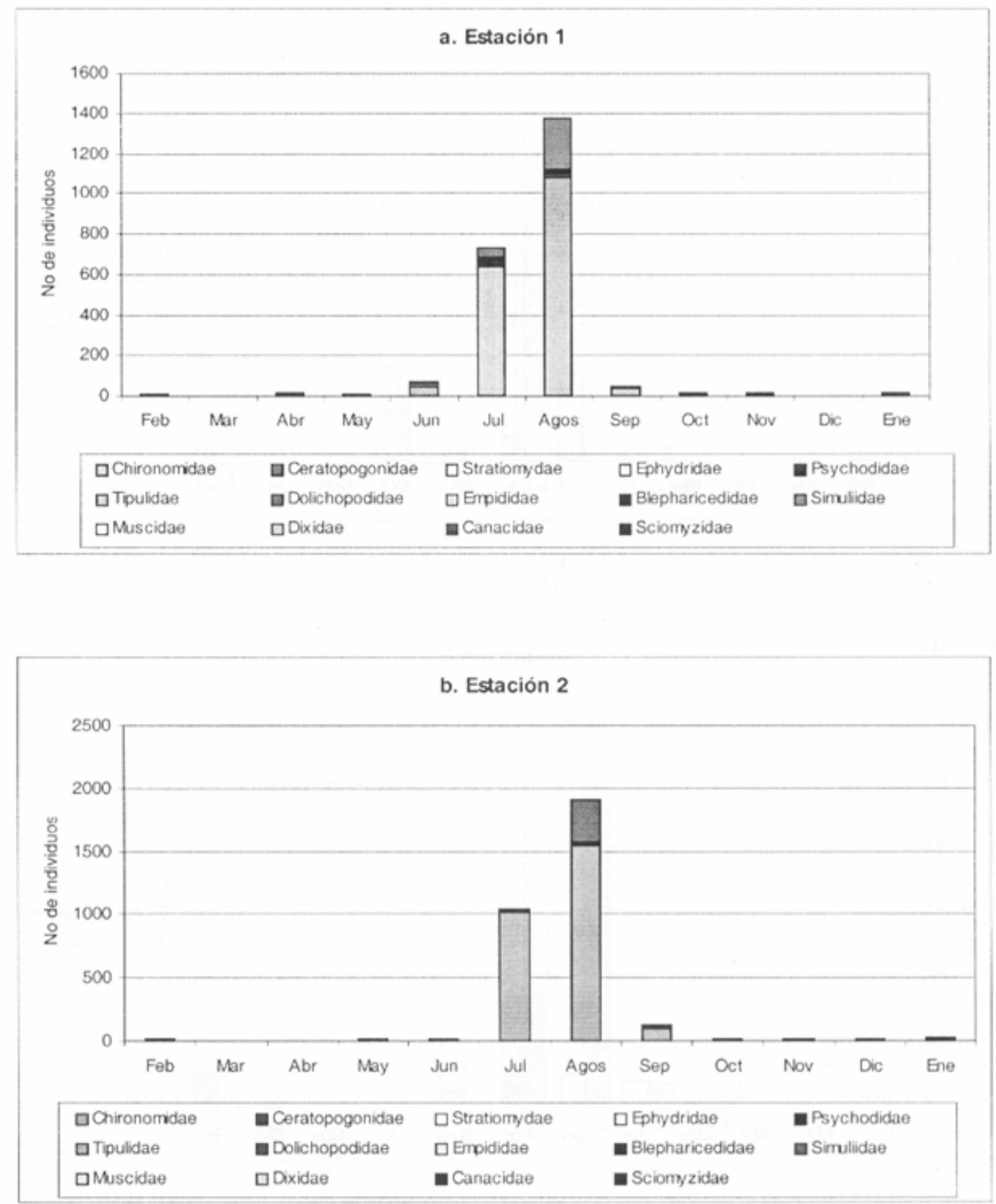

Fig. 5. Abundancia del orden Diptera en el río Villeta - Cundinamarca. 

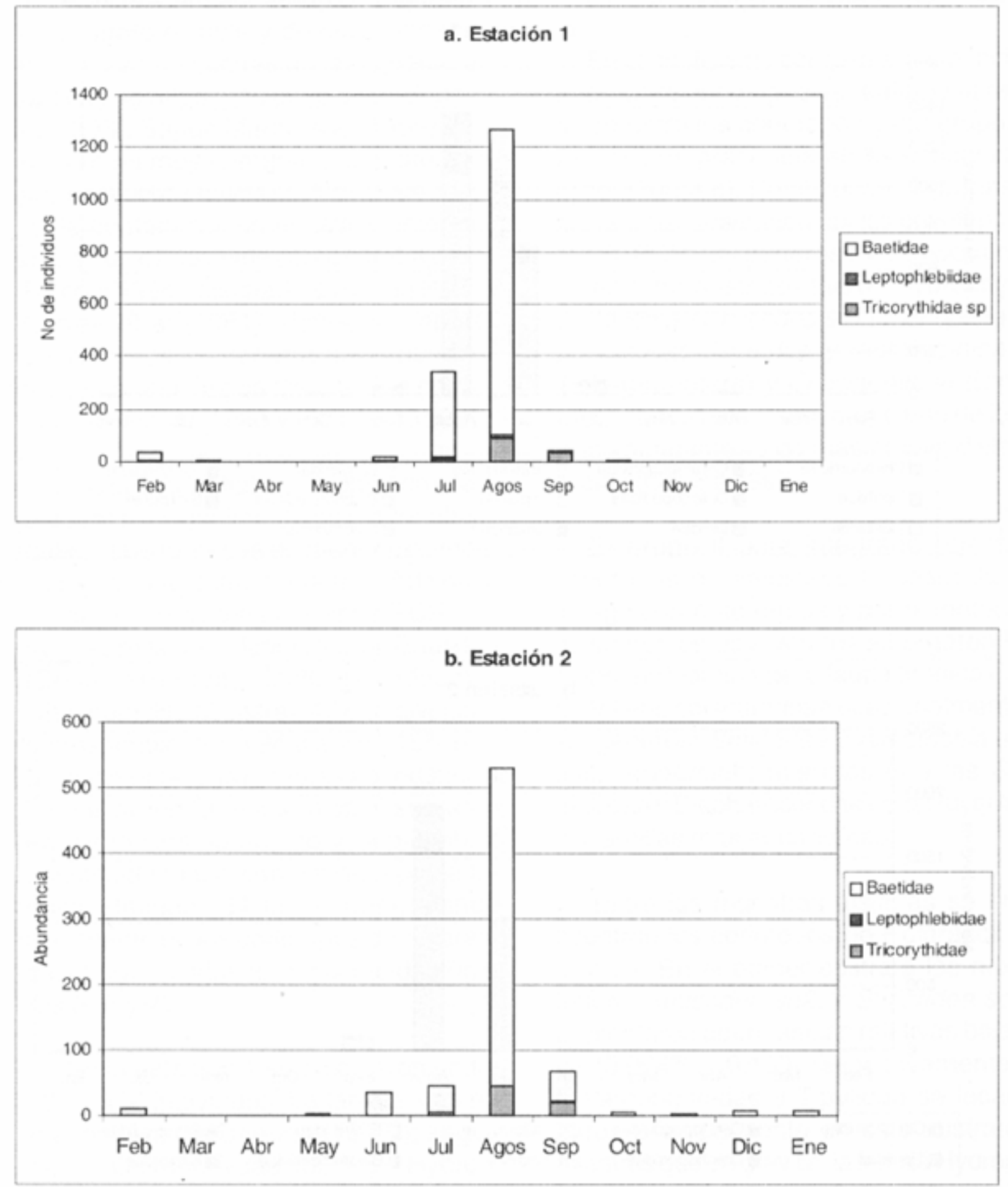

Fig. 6. Abundancia de los Ephemeroptera en el río Villeta - Cundinamarca. 

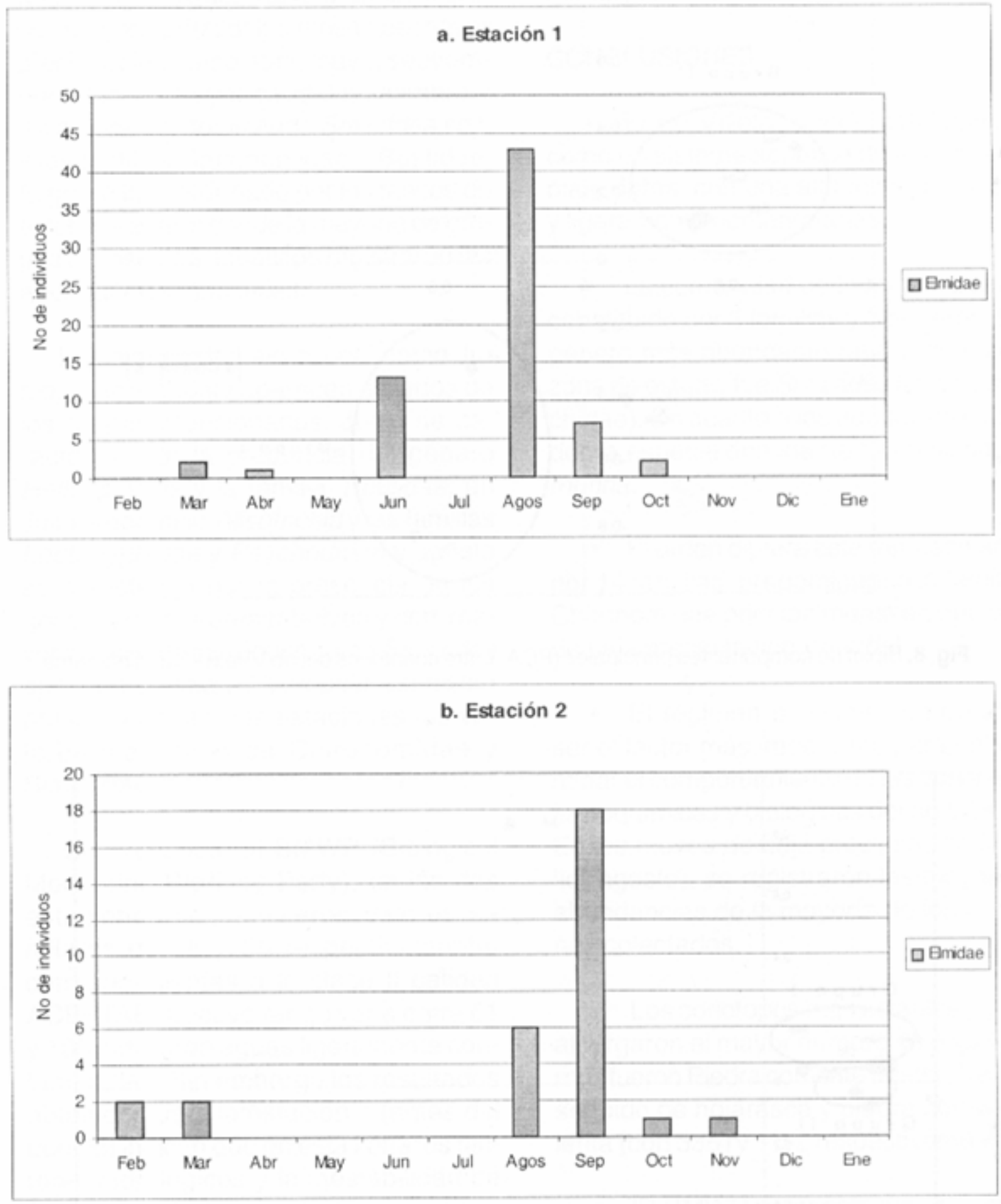

Fig. 7. Abundancia de los Coleoptera en el río Villeta - Cundinamarca. 


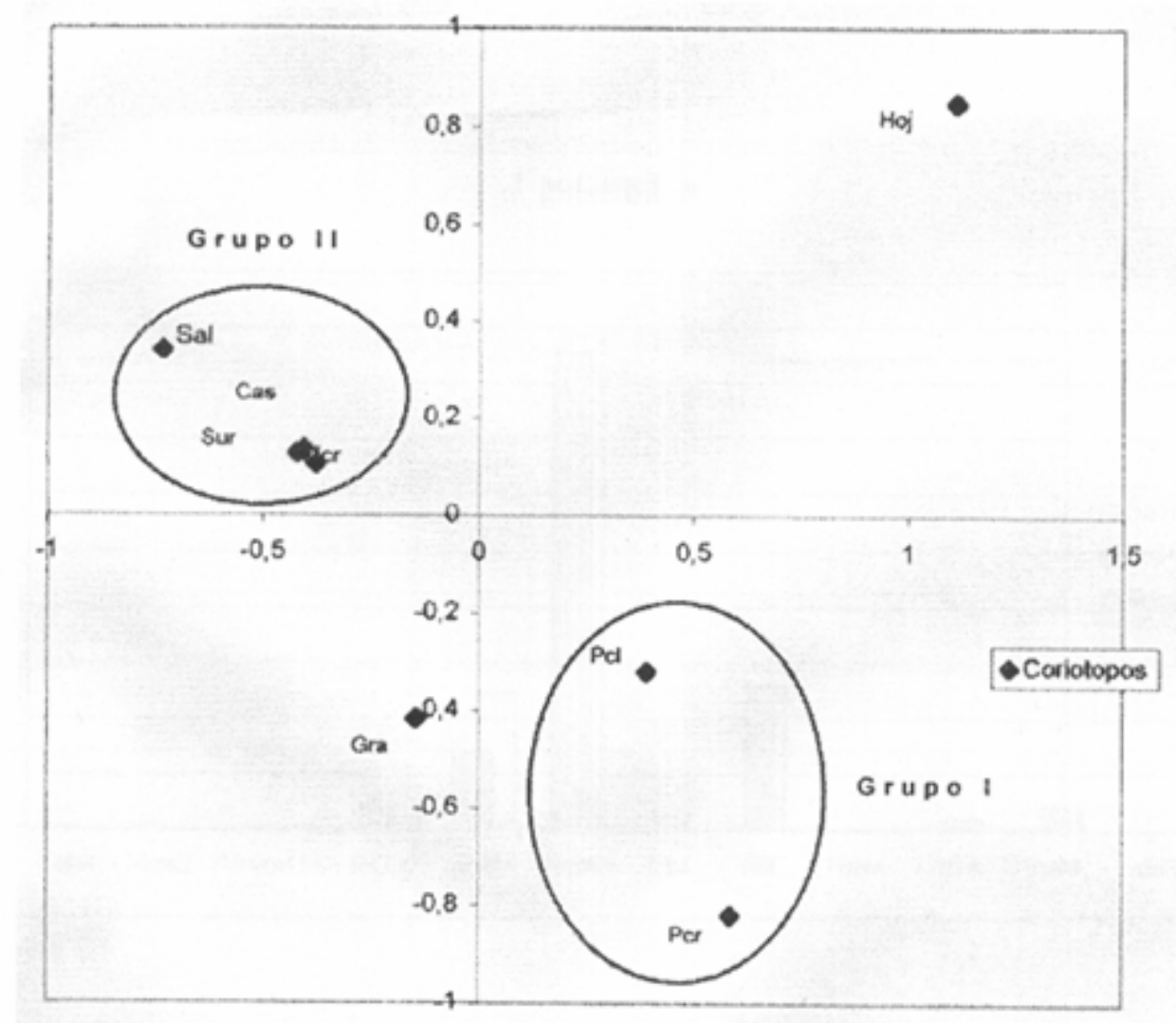

Fig. 8. Biplot de componentes principales (PCA) entre coriotopos del rio Villeta - Cundinamarca.

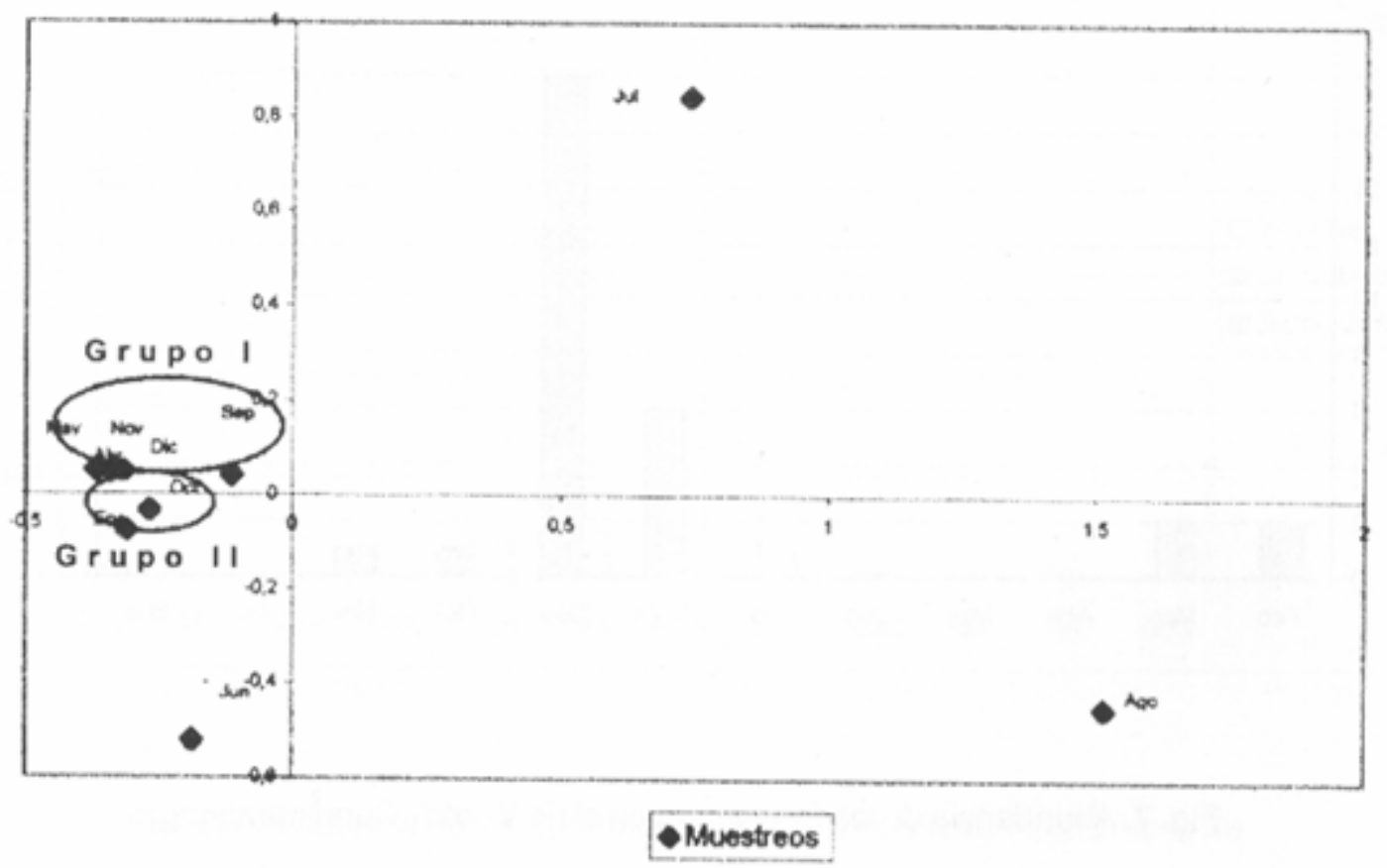

Fig. 9. Biplot de componentes principales (PCA) entre meses de muestreo. 
En relación con el análisis de ordenamiento (PCA) entre meses de muestreo (Figura 9) se evidencian 2 grupos; el grupo 1 conformado por los meses de mayor precipitación como abril, mayo, septiembre y los de mayor caudal noviembre y diciembre, predominando Smicridea sp1. y las familias Chironomidae y Baetidae. El grupo II, conformado por los meses de octubre y enero; donde la mayoría de grupos de insectos acuáticos registraron las abundancias más bajas.

Los meses de bajo caudal como Junio, Julio y Agosto aparecen aislados de los grupos mencionados. Junio se caracterizo por la presencia del género HeliCopsyche y la familia Tipulídae; en Julio predomino Alisotrichia y las familias Leptohyphidae y Psychodidae y agosto se caracterizo por la presencia de los géneros más representativos y con mayor número de individuos como Smicridea spl, Leptonema e Hydroptíla; asimismo presento en las dos estaciones los valores más altos de Chironomidae y Simuliidae.

Con respecto al BMWP (Biological Monitoring Working Party>, en las dos estaciones se obtuvieron valores similares de 96 y 95 respectivamente, correspondientes a la clase II calidad ACEPTABLE, cuyo rango varia entre 61 y 100 indicando aguas ligeramente contaminadas. Sin embargo los resultados obtenidos para la estación 1 (antes del pueblo) indican que en esta zona los factores hidrológicos y la inestabilidad de los suelos aledaños a la cuenca condicionan más directamente la diversidad y la abundancia de los diferentes grupos de insectos acuáticos, que los aportes de material orgánico provenientes del municipio de Vílleta.

\section{CONCLUSIONES}

- El río Villeta, puede catalogarse como un sistema acuático de aguas, turbias, duras, con una alta mineralización y ligeramente contaminadas.

- La comunidad de trichoptera esta constituido por 3 familias y 5 géneros. El género más abundante reportado en la zona de estudio fue SmiCridea (Hydropsychidae). En cuanto a los adultos colectados la especie dominante fue SmiCridea murina.

- El orden diptera esta representado por 14 familias, predominando la familia Chironomidae principalmente en épocas de baja precipitación y caudal.

- El régimen pluviométrico parece ser el factor más importante para determinar el comportamiento de las variables fisicoquímicas y biológicas del río Villeta. En los meses de baja precipitación (Julio- agosto), se registraron las mayores abundancias de la mayoría de los ordenes colectados.

- Los coriotopos más estables y que albergaron el mayor número de organismos fueron Piedra corriente rápida (3361), seguido de hojarasca y piedra corriente lenta (con 3361y 1112 respectivamente).

- El BMWP no constituye un método confiable para evaluar la calidad biológica del agua del río Villeta.

BIBLIOGRAFIA

ANGRISANO, E.B, (1995). Trichoptera. En: Ecosistemas de aguas continentales. Tomo III LOPRETO, E y TELL, G. La plata, República de Argentina. 
BENAVIDES, S. et al 1993. Estudios técnicos con fines de evaluación de la calidad del agua de la quebrada Lince (Labio Cundinamarca) Tesis Universidad Pedagógica Nacional. Santafé de Bogotá.

CORREA, M MACHADO, T y HOLDÁN, G. 1981. Taxonomía y ecología del orden Trichoptera en el departamento de Antioquiaa, en diferentes pisos altitudinales. En: Actual. Biol. Vol.10, N036; p35-48.

DOMINGUEZ, E.; M. D. HUBBARD y M.L. PESCADOR. 1994. Los Ephemeroptera en Argentina. Fauna de agua dulce de la republica de Argentina. Vol 33 (1), 142 p.

DOMINGUEZ, E.; HUBBARD M.D.; PETERS, W. L.\& MOLINERI, C. 2001. Ephemeroptera. En Fernández, H. R. \& Domínguez, E. (Eds). Guía para la determinación de los artrópodos bentónicos sudamericanos sudamericanos. 282 p.

FLINT, O. S. 1983. Studies of neotropical caddisflies, XXXIII: New Species from austral South América. (Tríchoptera). En: Smithsonian Contribution to Zoologie. N 377. p.p.1-4.

1991. Studies of Neotropical Caddisfiies, XLV: The Taxonomy, Phenology, and Faunistic of the Trichoptera of Antíoquia. Colombia. Smithsonian. Contributions to Zoology. 520: 1-113.

FLINT, O.; R. HOLZENTHAL y S. HARRIS. 1999. Catalog of the Neotropical Caddisflies (Insecta: Trichoptera). Ohio Biological Survey. Columbus, Ohio U.S.A. Pgs. 239.

MACHADO,I Y G, ROLDÁN, 1981. Estudios de las características físicas - Químicas y biológicas del río Anorí y sus principales afluentes. Actual. Biol. 10 (35): 3-19.

MANGEAUD, A.1999. Efectos de fuentes de contaminación puntual sobre las comunidades de insectos bentónicos en la cuenca del Suquía (Córdoba, Argentina). Rey. Soc. Entomol. Argent. 58(1-2): 218-222.

MATTHIAS, U y H.MORENO,1983. Estudio de algunos parámetros físico- Químicos y biológicos del río Medellín y sus principales afluentes. Actual.Biol. 12(46): 106-117.

MEJÍA, J.L; .W,.CHINCHILLA, O. ROZO. 1997. Comportamiento fisicoquímico de la Laguna de Iguaque (Boyacá - Colombia) y dinámica de la comunidad zooplanctónica (crustácea). Universidad Pedagógica Nacional. Bogotá.

MERRIT, R. W.; CUMMINS, K. W. 1996. An introduction to the aqua tic insects of North America. Third edition. Dubuque: Kendall - Hunt Publishing Co. 862 p.

MUÑOZ DE HOYOS, P. 1994. Simuliidae (Diptera) de Colombia: Distribución de las especies registradas. Revista de la Academia Colombiana de Ciencias Exactas, físicas y naturales. Vol XIX noviembre de 1994. 
MUÑOZ, D. \& R. OSPINA. 1999. Guía para la identificación genérica de los ephemeroptera de la sabana de Bogotá, Colombia. Ninfas y algunos géneros de adultos. Actual Biol 21 (70):pgs 47- 60.

PRAT, N. 1997. La problemática de la conservación de los ríos españoles como ecosistemas. Ecosistemas. 20/21: 42-47.

RAMíREZ, A. \& VIÑA, G. 1998. Limnología Colombiana aportes a su conocimiento estadístico. BP Exploration.

RINCÓN, M.E. 1996. Aspectos bioecológicos de los tricópteros de la Quebrada Carrizal. Rey. Soc. Entomol. Vol.22 № 2, Santafé de Bogotá.

1999. Estudio preliminar de la distribución altitudinal de los Trichoptera de la cordillera oriental Colombiana. En: Andrade, G; F. Fernández y G. Amat (Eds). Insectos de Colombia, volumen II. Estudios escogidos. Academia colombiana de ciencias Exactas, Físicas y Naturales. Santaté de Bogotá.

RINCON \& LADINO.1997. Calidad biológica de los sistemas acuáticos, del Santuario de Flora y Fauna de Iguaque. Unisalle Departamento de Química Biología. Diógenes vol 4, \#2.

ROLDÁN, G. 1988. Guía para el estudio de Macroinvertebrados acuáticos del departamento de Antioquia. FEN. Presencia. Bogotá.

Medellín. .1992. Fundamentos de Limnología Neotropical. Universidad de Antioquia.

2000. Los macroinvertebrados acuáticos y su uso como bioindicadores de la calidad del agua. En: Memorias del IV Seminario nacional de Limnología. Bogotá Noviembre 11 al 13.

RUIZ , J. L.; OSPINA R. Y RISS W. 2000. Guía para la identificación genérica de larvas de quironomidos (Diptera): Chironomidae) de la Sabana de Bogotá. II Subfamilia Chironominae. Caldasia 22 (1): 15-23.

URIBE, A. \& ROLDÁN, G.1975. Estudio comparativo de algunas características físicoquímicas y biológicas del embalse del Peñol (Nare). Actualidades biológicas. Vol.4.n 11 enero-marzo.

WIGGINS, G. B. 1996. Larvae of North American caddisfly genera(Trichoptera). University of Toronto Press. Toronto and Bufalo. 